\title{
Calcium, physical activity and bone health - building bones for a stronger future
}

\author{
Francesco Branca* and Silvia Vatueña \\ Istituto Nazionale per gli Alimenti e la Nutrizione, Via Adreatina 546, Rome, Italy
}

\begin{abstract}
Adequate provision of nutrients composing the bone matrix and regulating bone metabolism should be provided from birth in order to achieve maximal bone mass, compatible with individual genetic background, and to prevent osteoporosis later in life. Low calcium intake $\left(<250 \mathrm{mg} \mathrm{day}^{-1}\right)$ in children is associated with both a reduced bone mineral content and hyperparathyroidism. Optimal calcium intake is, however, still a matter of controversy. The minimisation of fracture risk would be the ideal functional outcome on which to evaluate lifetime calcium intakes, but proxy indicators, such as bone mass measurements or maximal calcium retention, are used instead. Calcium recommendations in Europe and the United States are based on different concepts as to requirements, leading to somewhat different interpretations of dietary adequacy. Minerals and trace elements other than calcium are involved in skeletal growth, some of them as matrix constituents, such as magnesium and fluoride, others as components of enzymatic systems involved in matrix turnover, such as zinc, copper and manganese. Vitamins also play a role in calcium metabolism (e.g. vitamin D) or as co-factors of key enzymes for skeletal metabolism (e.g. vitamins $\mathrm{C}$ and $\mathrm{K}$ ). Physical activity has different effects on bone depending on its intensity, frequency, duration and the age at which it is started. The anabolic effect on bone is greater in adolescence and as a result of weight-bearing exercise. Adequate intakes of calcium appear necessary for exercise to have its bone stimulating action.
\end{abstract}

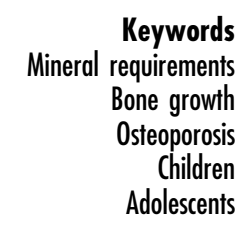

\section{Introduction}

Osteoporosis, a disease affecting several million people in the world, should be prevented from childhood by achieving maximal bone mass compatible with individual genetic background. It is even possible that prevention should start as early as during pregnancy, since maternal health and nutrition affects in utero bone growth and development ${ }^{1}$.

Bone mass increases until the third decade of life, then slowly decreases. In women, $15 \%$ of the peak bone mass will be lost in the first 5 years after menopause ${ }^{2}$ and up to $30-50 \%$ before the age of $70^{3}$, when menopause-related bone loss is concluded. The bone loss rate associated with the process of ageing is approximately $1 \%$ per year in men and women ${ }^{4}$. Therefore, having a larger bone capital and spending it more parsimoniously, i.e. reducing bone loss, delays the attainment of a bone density level at which fracture risk is high. Fracture incidence in individuals whose bone density is greater than $1 \mathrm{SD}$ above the mean is $50 \%$ lower at 80 years $^{4}$.
Peak bone mass is determined by the genetic background of the individual and by a combination of environmental influences that can explain up to $40 \%$ of the variance in bone mass, including usual body weight, weight-bearing physical activity and intake of certain nutrients known to compose the bone matrix or regulate its metabolism ${ }^{5}$. This review intends to summarise the role of calcium, other minerals and vitamins and physical activity in the achievement of the maximal peak bone mass allowed by a given genetic potential.

\section{Calcium}

Since approximately $70 \%$ of the bone weight is accounted for by calcium phosphate crystals, it is obvious to think of calcium as the first nutrient to be required for optimal bone growth. Very low calcium intake in children induces rickets, osteomalacia and growth retardation. Infants having intakes below $200 \mathrm{mg} \mathrm{day}^{-1}$ have radiographic appearance of rickets and 5-year-old Chinese children consuming less than $250 \mathrm{mg} \mathrm{day}^{-1}$ of calcium had 
reduced bone mineral content (BMC) and reduced growth compared to Hong Kong children having a calcium intake of $500 \mathrm{mg} \mathrm{day}^{-1}$ (Ref. 6). Marginally low calcium intake in children induces hyperparathyroidism ${ }^{7}$. $\mathrm{X}$-rays of children in Surinam did not show bone rarefaction $^{8}$, but a more sensitive indicator as forearm BMC relative to body size was indeed reduced in Gambian children?

Population Reference Intakes have recently been revised by the American Institute of Medicine ${ }^{10}$. Calcium requirements have been established using three indicators: risk of fracture, bone mass measurements and maximal calcium retention. The minimisation of fracture risk would be the ideal functional outcome on which to evaluate lifetime calcium intakes. Paradoxically, crosscultural comparisons have reported positive correlations between calcium intake and fracture risk ${ }^{11}$, but the crosssectional nature of the data and the absence of controls for confounding factors, such as genetic and lifestyle differences, points towards a fluke association. However, longitudinal clinical trials investigating the effects of calcium intake on fracture rates have not been carried out so far because of difficulties in the estimation of calcium intakes and the long follow-ups required.

Bone mass measurements are predictive of fracture risk and have been used as an indicator of outcome in observational studies and supplementation trials ${ }^{10,12,13,14}$. Observational retrospective and cross-sectional research reach non-uniform conclusions regarding the role played by calcium intake in bone mineral density (BMD) during childhood and adolescence. Differences in the methodology used, the age and mean calcium intake of the populations studied, and the skeletal sites selected to evaluate bone mass significantly contribute to the above discrepancies, making their interpretation more difficult. Overall, it appears that calcium intake is a determinant for bone mass acquisition from early childhood to prepubertal stages in healthy children with no hormonal imbalances $5,15,16,17,18$. During infancy and puberty, calcium absorption is maximised to meet the increased needs through hormonal mechanisms and, as long as calcium intake is above a minimum threshold around the RDA, its influence on bone mass gain is widely overwhelmed by genetic factors ${ }^{19,20,21}$. The above is especially true for the weight-bearing sites of the skeleton, which are more likely to be affected by nutritional influences $^{21,22}$. This may explain why studies linking current calcium intakes with BMD at the forearm in adolescents fail to find an association ${ }^{23,24}$, while investigations considering calcium intake during childhood, or for long periods of time during childhood and adolescence, report significant correlations with BMD at the hip and lumbar spine in children, adolescents and adults ${ }^{18,25}$.

As for the optimal calcium intake required to ensure the level of skeletal retention of calcium for maximal peak bone mass, supplementation trials carried out in US
Table 1 Dietary factors affecting calcium balance

\begin{tabular}{lll}
\hline & Decrease & Increase \\
\hline Absorption & Fibre & Food \\
& Phytate & Lactose \\
& Oxalate & Carbohydrates \\
& Caffeine & Lysine \\
& Fat & Fat \\
Excretion & Phosphorus & Protein \\
& Phosphorus & Sodium \\
& Alkaline ash & Chloride \\
& & Acid ash \\
\hline
\end{tabular}

children and adolescents consistently indicate that calcium intake should be increased above the current RDA in that country. Supplementation with $500 \mathrm{mg} / \mathrm{d}$ of calcium in children and adolescents with either low intakes or intakes close to the RDA significantly increases BMD at weight-bearing sites, at least initially ${ }^{26,27}$. Whether this effect is maintained later in life after supplement withdrawal, and whether differences with controls are increased or stabilised by maintaining calcium supplements for more than 1 year, has yet to be clarified ${ }^{28}$. In any case, usual consumption levels (around one half of the RDA) are insufficient for maximal peak-bone mass achievement ${ }^{15,26,27,29}$.

Maximal calcium retention is the intake level above which there is no additional increase in balance. It is related to maximal skeletal calcium and is the primary indicator to establish calcium requirements. Factors affecting calcium balance, i.e. bioavailability, physical activity and nutrient-nutrient interactions, are essential in setting the requirements.

Calcium absorption is regulated by a number of dietary and individual factors. It is enhanced when the needs are greater, such as in infancy and adolescence. Fractional calcium absorption is highest in infancy (60\%), decreases in childhood, then rises with puberty (34\%), stabilises in adulthood (25\% in young adults), and progressively decreases with ageing ${ }^{15,30}$. In extraordinary physiological conditions, such as pregnancy, oestrogens significantly promote calcium absorption to preserve the maternal skeleton. Generally speaking, fractional calcium absorption is inversely correlated to calcium intake ${ }^{31}$, meaning that absorption is more efficient when calcium is short in the diet. Protein-energy malnutrition reduces the efficiency of calcium absorption ${ }^{32}$, while recovery from malnutrition can enhance calcium retention up to $87 \%{ }^{33}$. Table 1 summarises the factors affecting calcium absorption and excretion. Absorption efficiency of calcium is maximal for dairy products and lower for vegetable sources, probably because fiber and phytates present in plant foods may inhibit calcium absorption ${ }^{34,35,36}$. However, the ingestion of calcium-rich plant foods may increase calcium retention indirectly by reducing the acid load of the overall diet and therefore, limiting urinary excretion of calcium. The opposite effect is associated 
Table 2 Adequate intakes of calcium in infants and children in the United States ${ }^{10}$

\begin{tabular}{lcl}
\hline Age group & Adequate intake $\left(\mathrm{mg} \mathrm{day}^{-1}\right)$ & \multicolumn{1}{c}{ Evidence considered } \\
\hline $0-6 \mathrm{~m}$ & 210 & Breast milk intake \\
$6-12 \mathrm{~m}$ & 270 & Breast milk + solid food intakes \\
$1-3 \mathrm{y}$ & 500 & Balance studies \\
$4-8 \mathrm{y}$ & 800 & Intervention studies \\
$9-13 \mathrm{y}$ & 1300 & Maximal calcium retention BMC \\
$14-18 \mathrm{y}$ & 1300 & Epidemiological evidence \\
\hline
\end{tabular}

with dairy product consumption, especially when high, because of the animal protein component. Together with animal protein and the acid load of the diet, sodium is a determinant dietary factor influencing obligatory urinary losses of calcium ${ }^{37,38}$.

Table 2 summarises the US Institute of Medicine consensus panel resolution on Adequate Intakes of calcium for different age groups and indicates the evidence considered to set the values. In the first year of life observational studies are taken into account. In older children, balance studies and studies on maximal calcium retention are instead considered.

The recommendation regarding optimal calcium intake is a matter of controversy. Fig. 1 illustrates the differences between European and US recommendations. Even within Europe there are differences between the UK and the Nordic region, for example. This is due both to a slightly different concept of requirements, (Population Reference Intake in the UK, Adequate Intake in the US), and to different data taken into account (for example, the European and the Nordic recommendations are not based on maximal retention). Recommendations for infants under 2 years are higher in Europe than in the US, while recommendations in older children and adolescents are higher in the US.

There is a wide spectrum of calcium intakes in different world populations. Fig. 2 shows data on children's intake in Europe, the US and in several developing countries. In the developed world calcium adequacy is generally good, although inadequacy may be argued according to the

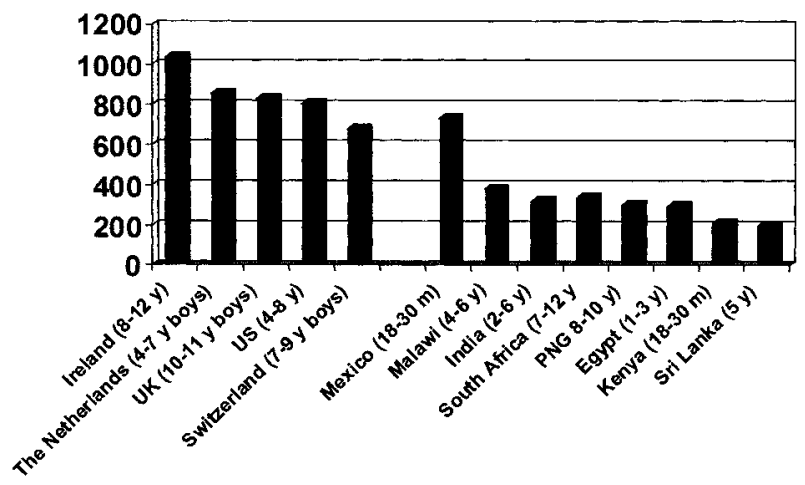

Fig. 1 Calcium requirements established by US and European expert committees. recommendation that is chosen. In the developing world there may be several areas of frank inadequacy.

Coverage of requirements could be achieved by the diet only, by fortified foods, by supplement consumption or by a combination of the different approaches. In the US, only about 25\% of boys and 10\% of girls aged 9 to 17 are estimated to meet the $\mathrm{NIH}$ recommendations because of low intake of dairy products ${ }^{39}$. In European diets dairy products are the major source of calcium. Coverage of requirements by diet only may be difficult in population groups that have to keep total energy intake low, in groups with high requirements that are not accustomed to consuming foods with high calcium density, or in lactose intolerant subjects ${ }^{40}$. For example, in Italian adolescents the consumption of milk decreases while that of dairy products does not increase until young adulthood, thus leaving a window of low intakes relative to requirements (D'Amicis, personal communication).

\section{Other nutrients}

Minerals and trace elements other than calcium are involved in skeletal growth, some of them as matrix constituents, such as magnesium and fluoride, others as components of enzymatic systems involved in matrix turnover, such as zinc, copper and manganese. Insufficient dietary supply of these nutrients results in reduced bone growth or in the formation of defective bone. Vitamins also play a role in calcium metabolism (e.g. vitamin D) or as co-factors of key enzymes for skeletal metabolism (e.g. vitamins $\mathrm{C}$ and $\mathrm{K}$ ). Some of the evidence relating those nutrients to bone growth and development is reviewed in this section.

Magnesium is involved in hydroxyapathite crystal formation and 50\% of the total body content of this mineral is stored in the skeleton. Clinical studies suggest a role for magnesium in determining skeletal mass but there is not enough evidence to give a recommendation about the intake required to maximise $\mathrm{it}^{10}$. One study has shown a correlation between dietary magnesium intake and BMD in postmenopausal women ${ }^{41}$. A four-year supplementation trial reports no effect of magnesium supplements on BMC in pre- and post-menopausal women ${ }^{42}$, while two other studies showed an effect of magnesium supplements on BMD in osteoporotic women, either alone $^{43}$ or in combination with calcium and oestrogen 


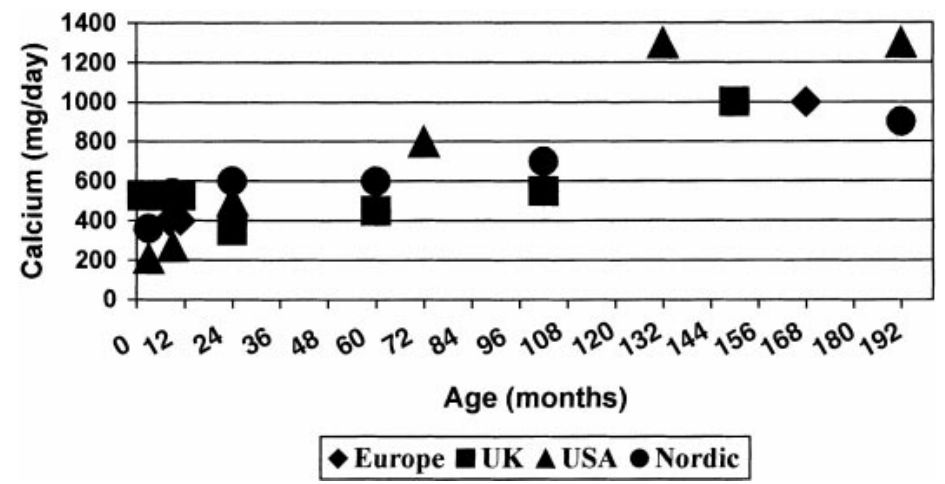

Fig. 2 Calcium intake in various world countries.

therapy ${ }^{44}$. Discrepancies between studies may well be caused by the baseline magnesium status of the enrolled subjects, since magnesium-deficient individuals are more likely to benefit from therapy than non-deficient volunteers.

Fluoride is also involved in the formation of hydroxyapatite crystals. Experimental deficiency leads to a delay in skeletal development in animals. Evidence in humans is controversial as to whether water fluoridation is associated with a higher $\mathrm{BMD}^{45}$. Indeed, excess fluoride may lead to brittler bones, more susceptible to fractures ${ }^{46}$. Zinc deficiency is typically characterised by the arrest of growth. The bones of zinc deficient animals are very thin and fragile, with a marked reduction of all the cellular elements, depressed bone formation and increased bone resorption ${ }^{47}$. Combined zinc and calcium supplementation in post-menopausal women has induced a smaller decrease in BMD compared to women treated with calcium only ${ }^{48}$. Copper is important for the mechanical characteristics of the bone matrix, such that the bones of copper deficient animals are less resistant to mechanical stress $^{49}$. Manganese deficiency causes reduced growth and skeletal abnormalities in animals and in humans, with decreased bone turnover ${ }^{50}$. Boron has not been studied in children, but in post-menopausal women supplementation of a conventional low-boron diet led to a decrease in urinary calcium excretion ${ }^{51}$.

Vitamin D is required for calcium absorption. A few minutes of sun exposure are sufficient for endogenous synthesis. However, at latitudes above $40^{\circ} \mathrm{N}$ and below $40^{\circ} \mathrm{S}$ vitamin D3 endogenous synthesis is absent during the winter months ${ }^{52}$. Based on serum 25(OH)D levels, a recommendation for Adequate Intake has been set at $5 \mu \mathrm{g} \mathrm{day}^{-1}$ in children of all ages ${ }^{10}$. Vitamin $\mathrm{C}$ is required for the synthesis of type I collagen (the main organic component of bone), for the subsequent extracellular modifications that allow formation of collagen crosslinks, and for the synthesis of other important matrix constituents, such as glycosaminoglycans. Patients affected by scurvy are also osteoporotic, but there is no information about optimal intakes. The antioxidant role of vitamin $\mathrm{C}$ might also be important to modulate skeletal metabolism $^{53}$. Vitamin $\mathrm{K}$ is required for the synthesis of functional osteocalcin, an important structural protein of the bone matrix. An increased fracture rate has been observed in vitamin K-deficient elderly ${ }^{54}$. Excess vitamin A intake may be detrimental to bone health. In a crosssectional and nested case-control study on a cohort of Swedish adult women, Melhus et $a l^{55}$ found a dosedependent correlation between vitamin A intake, reduced bone density, and risk of hip fracture. This may be a public health issue, since in Scandinavian countries vitamin A intakes reached levels up to three-fold the recommended allowances and was six-fold higher than in southern Europe ${ }^{56}$.

The peculiar role of micronutrients is demonstrated by the significant positive effects that multi-micronutrient supplementation had on bone growth of Saharawi refugee children, while mere protein supplementation had no effect compared to unsupplemented children (Lopriore and Branca, personal communication). From a public-health point of view, it is unclear whether mineral supplementation may have a positive impact on bone health in well-nourished populations, but it appears that mineral deficiency would substantially impair bone growth and mineralisation.

Most of the studies presented refer to adult skeletal metabolism and not to children's. Furthermore, the requirements of these minerals have not been calculated with reference to bone density and it has not been established whether the current recommendations are adequate to grant optimal skeletal mass during growth.

\section{Physical activity}

The functional demand imposed on bone is a major determinant of its structural characteristics. Biomechanical studies indicate that stress applied to a skeletal segment affects the geometry of the bone, the microarchitecture and the composition of the matrix ${ }^{57}$. Body weight, which represents the more constant load applied to an individual's skeleton, is a major determinant of bone 
mass. This is illustrated by the fact that normal weight and underweight individuals have lower bone mass and a greater risk for hip fractures than overweight or obese individuals, although diverse mechanisms other than the mechanical stress applied to bone may account for part of the differences ${ }^{58,59}$. Second to body weight, weightbearing physical activities, such as walking or gymnastics, represent the most important mechanical stimulus for bone formation ${ }^{60}$. Clinical trials and observational studies have shown that physical activity leads to greater bone density in children and adolescents and, to a lesser extent, in adults ${ }^{61,62,63}$. Conversely, a reduction in the loading history leads to a reduced bone cross section, as in children with neuromuscular diseases ${ }^{64}$. It is important to note that the effects of weight-bearing activities on bone mass and bone density is maximal at the hip and lumbar spine (weight-bearing sites of the skeleton) and very small, if any, at the forearm (non weight-bearing site). This may be a reason why studies choosing the latter as an outcome tend to understimate the role of physical activity on bone mass accretion ${ }^{23}$.

Physical activity has different effects on bone depending on its intensity, frequency, duration and the age at which it is started. A sustained level of activity leads to greater peak bone mass, as demonstrated by a 15-year longitudinal study in which physical activity was correlated to BMD at the lumbar spine at age 27 , especially when initiated well before puberty $^{65}$. However, intense exercise programs that lead to excessive weight loss and hormonal imbalances, such as amenorrhea in elite gymnasts, may be detrimental for bone health despite the high loading achieved during the training program ${ }^{66}$.

It is unclear whether the level of exercise affects the requirements for calcium or other nutrients. Calcium intake appears to modify the effect of gross motor activity on bone mass accretion in infants at moderately high levels of calcium intake, but at moderate to low calcium intakes, infants in a gross motor programme have less bone mass accretion than controls ${ }^{67}$. A meta-analysis of studies conducted in postmenopausal women has shown that the combination of calcium supplements (1000$1500 \mathrm{mg}$ ) and physical activity programmes leads to remarkable increases in BMD at the lumbar spine, while supplementation or physical activity individually have either marginal or no effects ${ }^{22}$. Thus, at least for calcium, adequate intakes appear necessary for the exercise to have its bone stimulating action.

\section{Conclusion}

The achievement of the full genetic potential of bone mass can be achieved by combining an adequate intake of nutrients required to manufacture bone tissue with high mechanical loads (weight bearing physical activity). Full coverage of mineral (calcium, magnesium, fluoride, zinc, copper, manganese) and vitamin (D, C and K) requirements should be granted throughout childhood and adolescence. However, mineral requirements for optimal skeletal growth are still a matter of controversy and warrant further investigation. Meanwhile, as high as possible calcium intakes should be achieved through a balanced diet and can also be facilitated by the consumption of fortified foods. Dietary factors impairing positive calcium balance (mainly animal protein and sodium) should be minimized. For vitamins and other minerals recommendations based on other physiological indicators should be followed. A good level of physical activity should be promoted in children of all ages through organised sport, leisure and everyday habits.

\section{References}

1 Wang YL, Wu H, Yi BL, LeBlanc J. Newborn bone mineral density and health care during pregnancy. J. Bone Miner. Metab. 1998; 16(3): 190-2.

2 Hui SL, Slemenda CW, Johnston CC. Baseline measurement of bone mass predicts fracture in white women. Ann. Intern. Med. 1989; 111: 355-61.

3 Mazzuoli G, Acca M, Pisani D. et al. Annual skeletal balance and metabolic bone marker change in healthy early postmenopausal women: results of a prospective study. Bone 2000; 26: 381-6.

4 Riggs B, Melton L. New Eng. J. Med. 1992; 327: 620.

5 Kelly PJ, Eisman JA, Sambrook PN. Interaction of genetic and environmental influences on peak bone density. Osteoporosis Int. 1990; 1: 56-60.

6 Lee WTK, Leung SSF, Ng MY. et al. Bone mineral content of two populations of Chinese children with different calcium intake. Bone and Mineral 1993; 23: 195-206.

7 Pettifor JM, Ross P, Moodley G, Shuenyane E. Calcium deficiency in rural black children in South Africa - a comparison between rural and urban communities. Am. J. Clin. Nutr. 1979; 34: 2187-91.

8 Luyken R, Luyken-Koning FWM. Studies on physiology of nutrition in Surinam. XII. Nutrition and development of muscular, skeletal and adipose tissues in Surinam children. Am.J. Clin. Nutr. 1969; 22: 519-26.

9 Prentice A, Laskey MA, Shaw J, Cole TJ, Fraser DR. Bone mineral content of Gambian and British children aged 0-36 months. Bone and Mineral 1990; 10: 211-4.

10 Institute of Medicine. Dietary reference intakes for Calcium, Phosphorus, Magnesium, Vitamin D and Fluoride. Standing Committee on the scientific evaluation of dietary reference intakes. Washington DC: National Academy Press, 1997.

11 Hegsted D. Calcium and osteoporosis. J. Nutr. 1986; 116: 2316.

12 Cummings S, Black D, Nevitt M. et al. Bone density at various sites for prediction of hip fractures. Lancet 1993; 341: 72-5.

13 Cummings S, Nevitt M, Browner W. et al. Risk factors for hip fracture in white women. N. Engl. J. Med. 1995; 332: 767-73.

14 World Health Organisation. Assessment of fracture risk and its application to screening for postmenopausal osteoporosis. Geneva: WHO, 1994.

15 Matkovic V. Calcium metabolism and calcium requirements during skeletal modelling and consolidation. Am. J. Clin. Nutr. 1991; 54: 245S-60S.

16 Boot A, de Ridder M, Pols H, Krenning E, de Muinck KeizerSchrama S. Bone mineral density in children and adolescents: relation to puberty, calcium intake, and physical activity. J. Clin. Endocrinol. Metab. 1997; 82: 57-62.

17 Ilich JM, Hangartner T, Baoshe A, Matkovic V. Relation of 
nutrition, body composition and physical activity to skeletal development: a cross-sectional study in preadolescent females. J. Am. Coll. Nutr. 1998; 17: 136-47.

18 Teegarden D, Lyle R, Proulx W, Johnston C, Weaver C. Previous milk consumption is associated with greater bone density in young women. Am. J. Clin. Nutr. 1999; 69: 1014-7.

19 Specker B, Beck A, Kalkwarf H, Ho M. Randomized trial of varying mineral intake on total body bone mineral accretion during the first year of life. Pediatrics 1997.

20 Ilich J, Badenhop N, Jelic T, Clairmont A, Nagode L, Matkovic $\mathrm{V}$. Calcitriol and bone mass accumulation in females during puberty. Calcif. Tissue Int. 1997; 61: 104-9.

21 Magarey A, Boulton T, BE C, Schultz C, Nordin B. Familial and environmental influences on bone growth from 11-17 years. Acta Paediatr. 1999; 88: 1204-10.

22 Specker BL. Evidence for an interaction between calcium intake and physical activity on changes in bone mineral density. J. Bone Min. Res. 1996; 11: 1539-44.

23 Kardinaal A, Ando S, Charles P. et al. Dietary calcium and bone density in adolescent girls and young women in Europe. J. Bone Miner. Res. 1999; 14: 583-92.

24 Maggiolini M, Bonofiglio D, Giorno A. et al. The effect of dietary calcium intake on bone mineral density in healthy adolescent girls and young women in southern Italy. Int. J. Epidemiol. 1999; 28: 479-84.

25 Sentipal J, Wardlaw G, Mahan J, Matkovic V. Influence of calcium intake and growth indexes on vertebral bone mineral density in young females. Am. J. Clin. Nutr. 1991; 54: 425-8.

26 Johnston CC, Miller JZ, Slemenda CW. et al. Calcium supplementation and increases in bone mineral density in children. N. Engl. J. Med. 1992; 327: 82-7.

27 Lloyd T, Andon MB, Rollings N. et al. Calcium supplementation and bone mineral density in adolescent girls. JAMA 1993; 270: $841-4$

28 Nowson C, Green R, Hopper J. et al. A co-twin study of the effect of calcium supplementation on bone density during adolescence. Osteoporos. Int. 1997; 7: 219-25.

29 Stallings V. Calcium and bone health in children: a review. Am. J. Ther. 1997; 4: 259-73.

30 Agnusdei D, Civitelli R, Camporeale A. et al. Age-related decline of bone mass and intestinal calcium absorption in normal males. Calcif. Tissue Int. 1998; 63: 197-201.

31 Ireland P, Fordtran JS. Effect of dietary calcium and age on jekjunal calcium absorption in humans studies by intestinal perfusion. J. Clin. Invest. 1973; 52: 2672-81.

32 Younoszai MK, Ghishan FK. In vivo intestinal calcium absorption in infant rats: normal and growth retarded. $J$. Nutr. 1979; 109: 573-9.

33 de Portela ML, Zeni S, Piazza N, Rio ME. Calcium balance in infants recovering from undernutrition. Nutr. Rep. Int. 1982; 26: $1045-51$.

34 Weaver C, Proulx W, Heaney R. Choices for achieving adequate dietary calcium with a vegetarian diet. Am. J Clin. Nutr. 1999; 70: 543S-8S.

35 Heaney R, Weaver C. Effect of psyllium on absorption of coingested calcium. J. Am. Geriatr. Soc. 1995; 43: 1-3.

36 Reid D, New S. Nutritional influences on bone mass. Proc. Nutr. Soc. 1997; 56: 977-87.

37 Nordin BEC, Need AG. The effect of sodium on calcium requirement. In: Draper HH, ed. Nutrition and osteoporosis. New York: Plenum Press, 1994: 209-30.

38 Devine A, Criddle R, Dick I, Kerr D, Prince R. A longitudinal study of the effect of sodium and calcium intakes on regional bone density in postmenopausal women. Am. J. Clin. Nutr. 1995; 62: 740-5.

39 NIH. Consensus Development Conference Statement. Osteoporosis Prevention, Diagnosis, and Therapy. March 27-29, 2000.

40 Infante D, Tormo R. Risk of inadequate bone mineralization in diseases involving long-term suppression of dairy products. J. Pediatr. Gastroenterol. Nutr. 2000; 30: 310-3.

41 Yano K, Heilbrun LK, Wasnich RD, Hankin JH, Vogel JM. The relationship between diet and bone mineral content of multiple skeletal sites in elderly Japanese men and women living in Hawaii. Am. J. Clin. Nutr. 1985; 42: 877-88.

42 Freudenheim JL, Johnson NE, Smith EL. Relationships between usual nutrient intake and bone mineral content of women 35-65 years of age: longitudinal and cross-sectional analysis. Am. J. Clin. Nutr. 1986; 44: 863-76.

43 Stendig-Lindberg G, Tepper R, Leichter I. Trabecular bone density in a two year controlled trial of peroral magnesium in osteoporosis. Magnes. Res. 1993; 6: 155-63.

44 Abraham GE, Grewal H. A total dietary program emphasizing magnesium instead of calcium: effect of the mineral density of calcaneous bone in postmenopausal women on hormonal therapy. J. Reprod. Med. 1990; 35: 503-7.

45 Kröger H, Alhava E, Honkanen R, Tuppurainen M, Saarikoski S. The effect of fluoridated drinking water on axial bone mineral density: a population-based study. Bone Miner. 2: 33 41.

46 Sowers M, Clark MK, Jannausch ML, Wallace RB. A prospective study of bone mineral content and fracture in communities with differentila fluoride exposure. Am. J. Epidemiol. 1991; 133: 649-60.

47 Holloway WR, Collier FM, Herbst RE, Hodge JM, Nicholson GC. Osteoblast-mediated effects of zinc on isolated rat osteoclasts: inhibition of bone resorption and enhancement of osteoclast number. Bone 1996; 19: 137-42.

48 Strause L, Saltman P, Smith KT, Bracker M, Andon MB. Spinal bone loss in postmenopausal women supplemented with calcium and trace minerals. J. Nutr. 1994; 124: 1060-4.

49 Jonas J, Burns J, Abel EW, Cresswell MJ, Strain JJ, Paterson CR. Imparied mechanical strength of bone in experimental copper deficiency. Ann. Nutr. Metab. 1993; 37: 245-52.

50 Fincham JE, van Rensburg SJ, Maras WFO. Mseleni joint disease - a manganese deficiency? S. Afr. Med. Journ. 1981; 60: $445-7$.

51 Nielsen FH, Hunt CD, Mullen LM, Hunt JR. Effect of dietary boron on mineral, estrogen and testosterone metabolism in postmenopausal women. FASEB J 1987; 1: 394-7.

52 Ladizesky M, Lu Z, Oliveri B, San Roman N, Diaz S, Holick MF, Mautalen C. Solar ultraviolet B radiation and photoproduction of vitamin D3 in central and southern areas of Argentina. J. Bone Miner. Res. 1995; 10: 545-9.

53 Leveille SG, LaCroix AZ, Koepsell TD, Beresford S, Van Belle G, Buchner DM. Do dietary antioxidants prevent postmenopausal bone loss? Nutr. Res. 1997; 17(8): 1261-9.

54 Hodges SJ, Akesson K, Verganud P. et al. Circulating levels of vitamins K1 and K2 decreased in elderly women with hip fracture. J. Bone Miner. Res. 1993; 8: 1241-5.

55 Melhus H, Michaelson K, Kindmark A. et al. Excessive dietary intake of vitamin A is associated with reduced bone mineral density and increased risk for hip fracture. Ann. Int. Med. 1998; 129: 770-8.

56 Cruz J, Moreiras-Varela O, van Staveren W, Trichopoulu A, Roszkowski W. Intake of vitamins and minerals. Euronut SENECA investigators. Eur. J. Clin. Nutr. 1991; 45(suppl 3): 121-38.

57 Lanyon L. Control of bone architecture by functional load bearing. J. Bone Miner. Res. 1992; 7(Suppl 2): S369-75.

58 Holbrook T, Barret-Connor E. The association of lifetime weight and weight control patterns with bone mineral density in an adult community. Bone Miner. 1993; 20 141-9.

59 Langlois J, Harris T, Looker A, Madans J. Weight change between age 50 years and old age is associated with risk of hip fracture in white women aged 67 years and older. Arch. Intern. Med. 1996; 156: 989-94.

60 Judex S, Gross T, Zernicke R. Strain gradients correlate with 
sites of exercise-induced bone-forming surfaces in the adult skeleton. J. Bone Miner. Res. 1997; 12(10): 1737-45.

61 Bailey D, McKay H, Milwald R, Crocker P, Faulkner R. A sixyear longitudinal study of the relationship of physical activity to bone mineral accrual in growing children: the university of Saskatchewan bone mineral accrual study. J. Bone Miner. Res. 1999; 14: 1672-9.

62 Nickols-Richardson S, Modlesky C, O'Connor P, Lewis R. Premenarcheal gymnasts possess higher bone mineral density than controls. Med. Sci. Exerc. 2000; 32: 63-9.

63 Slemenda CW, Miller JZ, Hui SL, Reister TK, Johnston CC. Role of physical activity in the development of skeletal mass in children. J. Bone Min. Res. 1991; 6(1): 1227-33.
64 Rodriguez JI, Garcia-Alix A, Palacios J, Paniagua R. Changes in long bones due to fetal immobility caused by neuromuscular disease. J. Bone Joint Surg. 1988; 70A: 1052-60.

65 Welten DC, Kemper HGC, Post GB. et al. Weight-bearing activity during youth is a more important factor for peak bone mass than calcium intake. J. Bone Min. Res. 1994; 9: 1089-95.

66 Voss L, Fadale P, Hulstyn M. Exercise-induced loss of bone density in athletes. J. Am. Acad. Orthop. Surg. 1998; 6: 34957.

67 Specker B, Mulligan L, Ho M. Longitudinal study on calcium intake, physical activity, and bone mineral content in infants 6-18 months of age. J. Bone Miner. Res. 1999; 14: 569-76. 